\title{
Psicólogos em forma[ta]cão: Cartografias de um esboço de autoanálise
}

\section{Psychologists in forma[ta]tion: cartographies of an self- analysis draft}

Nedelka Solís Palma*

Universidade Federal de Sergipe, Aracaju, Sergipe, Brasil

Valter A. Rodrigues** (in memoriam)

Faculdade Cásper Líbero, São Paulo, Brasil

Marcia Moraes***

Universidade Federal Fluminense-UFF, Niterói, Rio de Janeiro, Brasil

\begin{abstract}
RESUMO
Este artigo visa instigar o exercício crítico que toma como ponto de partida o vivido e o não-vivido na experiência da formação acadêmica em psicologia. A metodologia é cartográfica, lançando mão de dois conceitos da Análise Insitituicional: implicação e analisador. Tal método de pesquisa nos permite revelar o jogo das forças instituídas implicado no saber/fazer da formação em psicologia, num curso de graduação em psicologia, de uma instituição privada, no interior do estado da Bahia, no Brasil. Analisamos as relações entre o neoliberalismo e a formação em psicologia, fazendo o uso do conceito foucaultiano de governamentalidade. Apontamos o currículo como a peça-chave de uma formação tecnicista esvaziada de uma atitude ética e de potência crítica. Formação ou formatação? Concluímos que a formação nunca é apenas a produção de um profissional, mas a produção de uma subjetividade na qual ficam incorporados modos de pensar, agir, sentir e perceber o mundo.
\end{abstract}

Palavras-chave: Formação em Psicologia, Neoliberalismo, Currículo, Produção de subjetividade.

\begin{abstract}
This article aims to instill the critical exercise that takes as its starting point what was experienced or not in the academic training in psychology. The methodology is cartographic, using two concepts of Institutional Analysis: implication and analyzer. This research method allows us to reveal the established play of forces involved in knowledge/training in psychology, at a psychology graduation course of a private institution in the state of Bahia, Brazil. We examine the relations between neo-liberalism and formation in psychology, using the Foucauldian concept of governmentality. We point out the academic curriculum as a key piece of technical education empty of an ethical attitude and critical power. Training or formatting? We conclude that training is never just a professional
\end{abstract}


production, but production of a subjectivity in which are incorporated ways of thinking, acting, feeling and perceiving the world. Keywords: Training (formation) in Psychology, Neo-liberalism, Academic curriculum, Production of subjectivity.

\title{
1 I ntrodução
}

\subsection{Definindo um método para um objeto em movimento}

\author{
Não tenho estilo de vida: \\ atingi o impessoal, o que é tão difícil. \\ Clarice Lispector (1998)
}

A partir de um esboço de autoanálise ${ }^{1}$ este artigo visa investigar o exercício crítico que toma como ponto de partida o vivido e o não vivido na experiência de formação acadêmica, num curso de graduação em Psicologia de uma instituição privada, localizada no interior do estado da Bahia.

Nesta autoanálise, nada de análise psico, mas análise esquizo². E por uma razão simples, entre outras não tão simples: uma psicoanálise precisa de um sujeito e do seu mundo interior para analisar, no entanto, aqui, neste esboço de autoanálise, não há um sujeito, um indivíduo no sentido de um eu, uma personalidade que fala na primeira pessoa. Muitas vozes nesta escrita sobre a formação acadêmica das psicólogas e psicólogos - humanas e não humanas. Polifonias. As vozes de alguns colegas, o silencio gritante de outros, um diário de campo, alguns personagens, e a voz instigante dos intercessores ${ }^{3}$. Polifonias desta voz transversalizada por afetos, encontros, desencontros, artifícios, marcas, amigos, colegas, desassossegos, ressonâncias, conexões, devires, pensamentos...

Esta polifonia é heterogênese, multiplicidade, e não deve ser confundida com representação ou com um sujeito porta-voz de um grupo que fosse consultado para extrair democraticamente uma fala representativa, mesmo porque cada um faz sua voz falar o que essa voz pode.

Ao mesmo tempo, os pesquisadores são personagens que falam transversalizando, perpassando, atravessando uma voz que aqui se torna escrita. Voz nem singular, nem plural, mas voz no entre, na zona de indiscernibilidade eu/outrem onde pululam as multiplicidades. Esta voz não pretende nem gritar verdades, nem sussurrar lamúrias, nem lançar denúncias ressentidas. É uma voz anônima, transitória, nômade, heterotópica ${ }^{4}$. Uma voz menor ${ }^{5}$, voz fuga, um trânsito para as intensidades que pedem passagem.

Não se trata então das vidas empíricas dos pesquisadores enquanto estudantes de graduação em psicologia. Isso seria memorialismo. Aqui não estamos falando de "a vida" (artigo definido "a") - a vida 
empírica, cronometrada tal qual aconteceu, pois assim entraríamos numa narrativa de lembranças pessoais, assunto para uma literatura de confessionário. Vamos aqui trabalhar para extrair "uma vida"6 (artigo indefinido "uma") - aquela que é ao mesmo tempo impessoal e singular -, para transformar (neste caso através da cartografia) os encontros que fizeram dessa vida uma obra ${ }^{7}$, e, neste caso, a obra é uma formação acadêmica. Assim, quando falamos de uma vida estamos colocando-nos na imanência dessa vida, sem nenhum valor superior à própria vida. Então, "uma vida", estamos falando não das experiências de uma pessoa enquanto fatos, mas das intensidades que não são um continuum, que não estão na cronologia das vidas empíricas, mas que pulsam de vez em quando, e estamos tentando pegar essas pulsações para falar não de "a formação", mas de "uma formação". O importante são as conexões, as ressonâncias que esta escrita conseguir ativar.

Uma análise esquizo não trabalha com um sujeito já pronto, um pressuposto estabelecido a priori; trabalha com processos de singularização, isto é, produção de subjetividade. Por isso nesta escrita não enfatizamos um sujeito autor, mas devires que se atualizam numa processualidade constante, gerando literalmente a pessoa, máscara atrás da qual não há um rosto verdadeiro, mas outras máscaras. Artifícios.

A metodologia para pesquisar um objeto que, em primeiro lugar, não pré existe, mas se constrói na própria pesquisa, e, em segundo lugar, não é um objeto estático, mas está em constante movimento mudança. Não pode ser uma metodologia consumada que estabeleça passos a serem percorridos à maneira das ciências exatas que trabalham com recortes e enquadramentos fixos, pois estamos tratando com processos em curso e não queremos perder a sua dinâmica porque é ontológica. Lançando mão da cartografia (DELEUZE; GUATTARI, 1995) como método, o objetivo é traçar mapas processuais de um determinado território existencial. O que interessa ao cartógrafo é o plano das forças para mapear o jogo de relacionamento dessas forças que compõem o campo de experiência pesquisado. Sendo coerentes com seus postulados, Deleuze \& Guattari (1995) não estabelecem a cartografia como um campo metodológico com regras e procedimentos específicos. Para Amador e Fonseca (2009, p. 31) "a cartografia se oferece como trilha para acessar aquilo que força a pensar, dando-se ao pesquisador, como possibilidade de acompanhamento daquilo que não se curva à representação.".

Deleuze e Parnet (1998) afirmam que todos nós somos feitos de linhas de natureza diversas. Temos as linhas duras, de segmentaridade tais como a família, a escola, o trabalho, etc. As linhas de segmentaridade flexível atravessam sociedades e indivíduos, "traçam pequenas modificações, fazem desvios, delineiam 
quedas e impulsos" (DELEUZE; PARNET, 1998, p.145). A terceira é uma linha de fuga, linha de gravidade ou celeridade, abstrata, de desterritorialização. "Estas linhas não param de se remeter uma às outras. É por isto que não se pode contar com um dualismo ou uma dicotomia, nem mesmo sob a forma rudimentar do bom e do mau." (DELEUZE; GUATTARI, 1995, p.18). Rolnik (2007) afirma que a tarefa do cartógrafo é dar voz para os afetos que pedem passagem, e que ele deve estar atento às intensidades de sua época.

Todavia, podemos considerar a formação acadêmica como uma instituição. Para problematizar essa institucionalização da formação, vamos procurar na nossa caixa de ferramentas alguns dos conceitos metodológicos da Análise Institucional.

A Análise Institucional (AI) é uma abordagem que inventa ferramentas conceituais para analisar as instituições sendo que seu método de intervenção é a socioanálise desenvolvida por Lourau (1975). Segundo Hess (2004, p.23), "O que Lourau propõe em A Análise Institucional é um método de intervenção em situação que consiste em analisar as relações que as múltiplas partes presentes no jogo social mantêm com o sistema manifesto e oculto das instituições.". O objetivo é levar os grupos a uma autoanálise, isto é, o próprio grupo produz um conhecimento de si mesmo, "revelando o não dito institucional, o mal-estar existente na organização" (ALTOÉ, 2004 , p. 56). Da caixa de ferramentas conceituais oferecida pela Al, utilizamos basicamente dois conceitos: implicação e analisador.

Implicação é um conceito inovador que questiona a pretensiosa neutralidade que coloca o pesquisador em uma redoma, fora da situação investigada, asséptico e impassível, longe do objeto estudado. O conceito afirma que pesquisador e campo de pesquisa são articulados, estabelecendo-se um envolvimento do pesquisador com os sujeitos de sua investigação em uma implicação afetiva, política e ideológica que pode tanto enriquecer quanto deturpar a análise dos dados (PAULON, 2005). Assim, a implicação diz respeito a estar atento a estas possibilidades.

Analisador é aquilo que na situação institucional gera a problemática, isto é, o elemento que é possível problematizar para que atue como dispositivo prático para a análise. "Daremos o nome de analisador àquilo que permite revelar a estrutura da instituição, provocá-la, forçá-la a falar." (LOURAU, 1975, pág. 284, grifos do autor). Assim, um analisador pode ser um acontecimento, uma prática, um indivíduo ou um dispositivo cujo funcionamento revela o que na estrutura social se mantém oculto, inconfessável, impensado (RODRIGUES; SOUZA, 1987), sendo assim naturalizado. Para Baremblitt (2002), um analisador é um dispositivo que revela o jogo de forças do instituído. Desse modo, resumimos as principais linhas da metodologia que utilizamos para investigar o objeto formação acadêmica em psicologia a partir da experiência que definimos acima como autoanálise - a 
cartografia é a inspiração chave do método: o que está em jogo é traçar um mapa processual das forças que se fazem presentes no território pesquisado; as ferramentas metodológicas remontam à análise institucional, principalmente em dois conceitos: implicação e analisador.

As observações participantes foram realizadas durante as aulas ministradas aos graduandos de Psicologia da instituição privada já mencionada, de diferentes períodos do curso, no ano letivo de 2008. As observações foram registradas em notas no diário de campo.

\title{
2 Contextualizando a experiência: neoliberalismo e educação
}

\subsection{Analisador: ensino superior privado}

\author{
Compreender é primeiro compreender \\ o campo com o qual e contra o qual cada um se fez. \\ Pierre Bourdieu (2005)
}

Nosso objeto de pesquisa exige abordarmos dois pontos: o ensino superior, num sentido mais geral e, em particular, o setor privado. Ao comentar a limitação do acaso que reuniu os estudantes naquela sala de aula, especificando que essa era a única opção que oferecia a cidade $^{8}$, referimo-nos ao fato - prioritário no Brasil - da privatização do ensino superior ${ }^{9}$.

Sendo a educação um direito de cidadania cuja garantia é dever do Estado, como é que no caso dela ser superior, perde sua condição de direito e passa a ser uma mercadoria comercializada pelos donos do capital? É precisamente essa ação desterritorializante que Deleuze e Guattari (1976) apontaram como traço característico do capitalismo, em virtude da qual infiltra no tecido do socius sua axiomática despótica, agora chamada de neoliberalismo ${ }^{10}$. Empresas estatais e serviços públicos são privatizados, e assim o Estado passa a ser mínimo $^{11}$. Nessa cruzada expansionista, os experts apontaram para a incompetência estatal no gerenciamento da economia utilizando, basicamente, duas estratégias discursivas conjugadas. Por um lado, elaboraram um discurso muito bem articulado fundamentando suas análises num jargão específico que Bourdieu e Wacquant (2000) chamaram de "La nouvelle vulgate planétaire", uma estranha nova língua que está em todas as bocas, martelando constantemente palavras como: globalização, flexibilidade, governança, empregabilidade, nova economia, empreendedorismo e gerenciamento. Consideram essa nova vulgata planetária um imperialismo simbólico de efeitos perniciosos por ser naturalizada e incorporada em todos os discursos. A outra estratégia consistiu no que Emir Sader (2003) considerou como uma das operações teóricas 
mais bem sucedidas do neoliberalismo, isto é, polarizar o debate na dicotomia estatal/privado eliminando assim um termo essencial - o público.

\begin{abstract}
O polo oposto ao estatal, nesse esquema, é a negação da cidadania, é o reino do mercado, aquele que, negando os direitos - não há lugar para eles no mercado - nega a cidadania, e o indivíduo como sujeito de direitos. [...] o público se identifica com a democracia, seja pelo compromisso com a universalização dos direitos, seja pela possibilidade de controle pela cidadania, enquanto que ao mercantilizar esferas da sociedade - privatizando-as - se retira da cidadania a capacidade de controle sobre elas. A polarização essencial não se dá entre o estatal e o privado, mas entre o público e o mercantil. (p.3, grifos nossos).
\end{abstract}

Entendemos, assim, como o acaso que reuniu o grupo de estudantes foi limitado por escolhas políticas que restringem drasticamente as experiências da formação profissional ao considerar o ensino superior um item de consumo e não um direito de cidadania. A diferença entre ensino público e privado diz respeito principalmente à lógica a partir da qual cada setor se movimenta. O ensino superior público é organizado em universidades que associam ensino, pesquisa e extensão, já no ensino superior privado predominam faculdades isoladas ${ }^{12}$, orientadas por uma racionalidade pautada na lógica da acumulação de capital, pela qual para obter maiores lucros reduzem o ensino à transmissão de conteúdos, eliminando a pesquisa e a extensão.

O projeto neoliberal não se esgota na expansão econômica via privatização e desestatização de serviços públicos, todavia, "se propõe a reformar o social e o político de acordo com os renovados interesses do capital" (SILVA, 1995, p.252). Na verdade, é a própria alma humana que é capitalizada. Para Guattari e Rolnik (2005):

Elas [as forças sociais que administram o capitalismo]
entenderam que a produção de subjetividade talvez seja
mais importante do que qualquer outro tipo de produção [...]
Tais mutações da subjetividade não funcionam apenas no
registro das ideologias, mas no próprio coração dos
indivíduos, em sua maneira de perceber o mundo, de se
articular com o tecido urbano, com os processos maquínicos
do trabalho e com a ordem social suporte dessas forças
produtivas. (p.34)

Pesquisando esse poder sobre a vida, Michel Foucault (1999) começa conceituando-o como biopoder ${ }^{13}$ : técnicas disciplinares e biopolítica. Prosseguindo na sua genealogia, o pensador lança o conceito de governamentalidade para analisar "o problema de como ser governado, por quem, até que ponto, com que fim, por que métodos" 
(FOUCAULT, 2008b, p.119). Com esse neologismo, Foucault vincula práticas de governo exercidas pelo estado (governar) e modos de pensamento (mentalidade) (LEMKE, 2000) que são produzidos por essas práticas nas quais governar tem um sentido mais amplo de "conduzir condutas" (FOUCAULT, 1995) e de governo de si. Em Nascimento da biopolítica, Foucault (2007) pesquisa a genealogia de duas formas específicas de governamentalidade: a do liberalismo como uma nova maneira de governar a partir de uma Razão de Estado e a do neoliberalismo. Este, opera um duplo movimento que Ihe permite, por um lado, expandir o mercado além de sua dimensão econômica ao infiltrar-se nas relações sociais e nos comportamentos individuais, e, por outro, constituir-se na substância ontológica do ser social, padrão e lógica axiomática "desde a qual, com a qual e na qual deveriam funcionar" (COSTA, 2009, p.174) tanto a sociedade quanto o indivíduo, o que equivale a dizer que o mercado se torna a própria governamentalidade. Temos aqui, uma sofisticada tecnologia de poder que investe na produção de um novo indivíduo - o Homo economicus -, aquele que se torna ele mesmo o seu próprio capital em "uma espécie de individualismo que envolve moldar a vida da pessoa como a empresa de si mesma" (PETERS, 2002, p.221).

Na nova versão do humano, as capacidades, destrezas, aptidões e habilidades das pessoas se tornam valor de troca, constituindo-se no capital com o qual cada um conta para cuidar de si mesmo com a mesma lógica que um empresário cuida da sua empresa. É a construção de um Eu/S.A. pelo gerenciamento de um eu-empresa. Isto não é uma simples metáfora, mas a produção de um tipo de subjetividade que serializa indivíduos obcecados pela competitividade e pela exigência constante de investir em si mesmos com um único objetivo: acumular capital humano para incrementar seu valor no mercado de trabalho. A isto chamam de empreendedorismo, qualidade vital para a empregabilidade.

Podemos inferir a importância da educação em geral e da formação acadêmica em especial nesse tipo de governamentalidade neoliberal. Veremos como esse novo ethos empresarial que gira em torno da cultura do empreendedorismo tem sido abraçado, cultivado e venerado pela sociedade em geral, pela família, pelo Estado, pela mídia, pelas instituições, até chegar na nossa sala de aula, no currículo e na questão das competências na formação profissional.

\section{Uma cartografia do saber: Desemaranhando linhas}

\subsection{Analisador: grade curricular}

O currículo é lugar, espaço, território. O currículo é relação de poder. 
O currículo é trajetória, viagem, percurso. O currículo é autobiografia, nossa vida, curriculum vitae: No currículo se forja nossa identidade.

O currículo é texto, discurso, documento. O currículo é documento de identidade. Tomaz Tadeu da Silva (SILVA, 1999).

Na nossa sala de aula, o currículo governa mentes. Governamentalidade nos corredores, nas salas, nas transparências que xerocam o já pensado, nos discursos do já dito, nas disciplinas que disciplinam 0 pensamento. Nas grades curriculares a governamentalidade reluz (CORAZZA, 2001). Este é seu centro de operações. O currículo fabrica interiores (BAPTISTA, 2000) no corpo do punhado de estudantes que querem ser psicólogas e psicólogos. Cotidianamente uma identidade vai sendo esculpida: a identidade do psicólogo.

Uma amiga que não via há muito tempo, ao me cumprimentar me diz, talvez para me agradar: - Você já está parecendo toda uma psicóloga! Murchei. Para aliviar minha angústia, respondi com um sorriso amarelo: - Só se for uma psicolouca! Murchei mesmo, ao pensar que eu podia estar projetando a tal "identidade do psicólogo". A sensação corporal foi a de vestir uma daquelas fantasias carnavalescas que desfilam no sambódromo com excesso de pesados adereços equilibrando-se na minha cabeça. O problema seria na hora da clínica, ao inclinar-me no divã, toda a parafernália cairia soterrando aquele coitado que por estar acamado não poderia nem fugir! Murchei mesmo, ao me visualizar incorporando a dita "identidade profissional" tão cara para alguns psicólogos sérios que formam psicólogos e para muitos dos que estão sendo formados (...)

Touché! $O$ comentário de minha amiga me deixou preocupada. O que, segundo ela, devia ser um elogio, penetrou como a ponta de um dardo na minha pele. Sei que as pessoas têm mania de incorporar estereótipos, mas, e se não fosse apenas "o visual" do que ela considera ser uma psicóloga? Inventariar. Gramsci (1984) diz que o início da elaboração crítica deve ser um inventário da infinidade de traços sem benefício, recebidos durante nosso percurso histórico. Então, este estágio clínico deve começar por esse inventário: o que vejo nessa coluna dos 'sem benefício' são os traços de um humanismo atávico e os dissimulados "microfascismos, sempre à espera de cristalizações" (DELEUZE \& GUATTARI, 1995, p.18). A ponta do dardo enfiado na minha pele está doendo e não quero anestesiar a dor. Inventariar. A dor me diz que devo continuar atenta, que ainda carrego o ranço de humanismos que se colaram na minha pele feito tatuagem. A operação de raspagem pode ser dolorosa... Necessária. Inventariar..... ${ }^{14}$. 
Governamentalidade do currículo: práticas de governo exercidas pelo Estado - Diretrizes Curriculares para os Cursos de Psicologia - e modos de pensar que são produzidos por essas práticas nas quais governar tem um sentido mais amplo de conduzir condutas e de governo de si - produção de uma identidade profissional, uma subjetividade prêt-à-porter (ROLNIK, 2007). Na colação de grau, ganha documento de identidade.

Assim, desemaranhando linhas nas miudezas do currículo, fomos encontrando espaços barrados. Logo entendemos que se tratava de um interceptor: aquilo que intercepta, que barra o acesso ou a passagem, que torna impossível o funcionamento do pensamento, mas, sobretudo, aquilo que capta ou apreende o que é dirigido a outrem, sem que disso se apercebam nem os que emitem, nem os que recebem. Na aula de psicologia, o que é interceptado, barrado, apanhado na passagem é o agenciamento das forças ativas, a atualização de virtualidades, os artifícios, as invenções, a criação de mundos. Nas cadeiras da aula de psicologia, corpos separados do que eles podem se entregam dóceis aos desígnios de alguma coisa que não está neles.

Sem dúvida, não consideramos o currículo como um objeto dado, portador de uma verdade última, uma essência. Lembremos que estamos cartografando, isto é, estamos no coração mesmo da processualidade que diz respeito ao jogo de forças que criam o objeto que estamos pesquisando. Sobre o assunto, encontramos no diário de campo (2008):

[...] um dos gerentes veio da capital e nos reuniu no Centro de Cultura para comunicar algumas mudanças importantes. Disse que falava em nome da "mantenedora" (essa vulgata é muito engraçada, aqui, mantenedores somos nós e o Estado com os ProUni, Fies, etc.). Falou sobre a preocupação com a educação, com a qualidade, com o projeto de formar profissionais competitivos, criativos e empreendedores, que continuaremos com essa missão, mesmo com a crise, o mercado, o petróleo, vocês entendem, temos que fazer cortes (é claro que não nas mensalidades!). A operação tesoura é no salário dos professores (horistas), é na carga horária, na grade curricular; não mais monografia - isso gasta muito papel (somos ecológicos), muito orientador - a cotação agora é por 2/horas-aula semanais, 10 formandos/orientador; isso dá 10 minutos por semana para cada "cliente"; idem para a supervisão de estágio. É claro que o professor termina trabalhando de graça porque ninguém consegue orientar nessas condições: orientaçõesrelâmpago (uma colega está treinando para falar bem rápido e poder otimizar os 10 minutos semanais). Alguém com muita indignação e sotaque caribenho perguntou se o MEC permitia isso, - é claro, respondera o mercador, tudo está dentro dos mínimos do MEC: pesquisa mínima, horário mínimo, currículo mínimo, salário mínimo, orientação 
mínima, supervisão mínima, tudo controlado por um Estado mínimo. Fiquei intoxicada de indignação e raiva. A decadência desse interceptor conseguiu me deixar por uns dias encolhida, num estado mínimo de tristeza. Fui socorrida pelo poeta. O Manoel (Barros, 2006) me disse que eu estava num estado transitório de musgar e que tinha que aprender a fazer entraduras nas palavras. Foi o que fiz.

Silva (1999) propõe uma definição para currículo e "teoria do currículo" e nos apresenta uma bela sequência iniciando por problematizar a própria noção de "teoria", que vai da perspectiva representacional - hegemônica - até a perspectiva do pósestruturalismo que problematiza o viés representacional, argumentando que a descrição simbólica, linguística da realidade (teoria) não pode ser separada de seus "efeitos de realidade", pois ao descrever o "objeto", a teoria o produz, inventando-o num processo circular pelo qual a "teoria" descreve como descoberta algo que ela própria criou. "Ela primeiro cria e depois descobre, mas, por um artifício retórico, aquilo que ela cria acaba aparecendo como uma descoberta" (SILVA, 1999, p.12). Daí as naturalizações tão comuns no discurso científico que parte de 'objetos reais'; não que eles não existam, mas são atravessados pelo perspectivismo, isto porque a percepção que temos do objeto não é direta, é mediada pela linguagem e pela cultura. Assim, as perspectivas pós-estruturalistas realizam um deslocamento ao focar o discurso e seus efeitos no lugar do conceito.

Para o autor curriculista, uma vantagem desse deslocamento é que as definições perdem seu essencialismo ontológico para serem contextualizadas historicamente. Por exemplo, no caso do currículo, cada teoria - quer seja tradicional, crítica ou pós-crítica - usa diferentes critérios para selecionar quais conhecimentos serão incluídos nas grades curriculares, sendo o critério principal o tipo de pessoa que cada teoria considera ideal para a sociedade que quer promover. Portanto, as teorias do currículo estão implicadas com "uma questão de 'identidade' ou de 'subjetividade'. Se quisermos recorrer à etimologia da palavra 'currículo', que vem do latim curriculum, 'pista de corrida', podemos dizer que no curso dessa 'corrida' que é o currículo, acabamos por nos tornar o que somos." (SILVA, 1999, p.15). As teorias críticas e pós-críticas chamam a atenção para as relações de poder envolvidas nessa operação. Conexões entre saber, identidade e poder perpassam as grades curriculares, portanto "não é mais possível alegar qualquer inocência a respeito do papel constitutivo do conhecimento organizado em forma curricular e transmitido nas instituições educacionais" (MOREIRA; SILVA, 2005, p.20-21). 
$\mathrm{Na}$ grade curricular de psicologia, não seria importante incluir o estudo das teorias do currículo, sendo este um dispositivo de produção de subjetividade e de saber-poder?

Nosso curso teve duas mudanças de grade curricular. O que vemos é que essas mudanças dizem respeito unicamente ao remanejamento tirar ou colocar - disciplinas, diminuição da carga horária, que mais tem a ver com a lógica de mercado e não com a qualidade do ensino.

\begin{abstract}
Os sentidos produzidos em torno de reformas curriculares, em sua grande maioria, significam currículo como um meio ou instrumento para se ter acesso a algo posterior. Esses sentidos provocam intensa desvalorização do currículo, significando-o como ferramenta de substituições de disciplinas, naturalizando e cristalizando as concepções curriculares hegemônicas. Mas, a questão é mais séria, pois, envolve questionar o lugar de professor, de psicólogo e da própria Psicologia. (BERNARDES, 2004, p.3).
\end{abstract}

Esses questionamentos fazem parte deste esboço de esquizoanálise, mas continuemos agora com o analisador currículo e voltemos para a sala de aula com o grupo de estudantes que querem ser psicólogas e psicólogos.

\title{
3.2 A aula de psicologia pode ser uma aula de escultura, de culinária ou de guerra ${ }^{15}$
}

A escultura está prestes a ganhar vida e documentação. Passaram-se cinco anos e o grupo de estudantes está formando. Muito estresse, nervosismo e angústias com o trabalho de conclusão de curso. Desta vez, todos têm que fazer a pesquisa - mesmo que mínima - e apresentá-la, cada um, sozinho, para a banca.

A culinária fica por conta do currículo. Um monte de receitas que o jargão refinado dos experts chama de conhecimento técnico, muito valorizado pelos acumuladores de capital humano. Nós que aqui estamos sabemos que as receitas não passam de conteúdo fragmentado em disciplinas que ficam pairando no ar, separadas do que podem ao não estabelecer vínculo nenhum com o mundo que habitamos. Todavia, a cartografia desse saber mostra as linhas duras, duplamente sedimentadas nas disciplinas. Primeiro, enquanto tecnologia de biopoder - conforme vimos em companhia de Foucault - as disciplinas são "métodos que permitem o controle minucioso das operações do corpo, que realizam a sujeição constante de suas forças e Ihes impõem uma relação de docilidade-utilidade" (FOUCAULT, 2008c, p.118.). Em segundo lugar, as disciplinas enquanto ramos do conhecimento - saber organizado em matérias que a escrita permite arquivar (FOUCAULT, 1972), numa operação de disciplinarização do 
saber pela qual todo novo saber já é produzido como fazendo parte de tal ou qual compartimento do arquivo, dando assim lugar às especializações que permitem a proliferação do arquivo.

Colocando isso no contexto do currículo, a disciplinarização do saber nos remete à imagem de um condomínio onde cada disciplina fica trancafiada no seu solipsismo. Gallo (1995) chama a atenção para "o efeito pernicioso da compartimentalização: os estudantes - e mesmo os professores - não são capazes de vislumbrar qualquer possibilidade de interconexão entre as várias gavetas dos arquivos" $(s / p)$.

Na nossa sala, em geral, ao longo desses cinco anos, as aulas foram de culinária. Salvo raras exceções, nossos professores se pareciam com arquivistas (GALLO, 1995), manipulando gavetas e xerocando conteúdos. A plateia em silêncio copia as receitas das transparências projetadas no quadro. Não é permitido mudar os ingredientes. Os cardápios são de países distantes. "O estudante apenas aprende as técnicas e busca o cliente para aplicá-las" (GOMIDE, 1998, p.74).

Governamentalidade neoliberal na nossa sala de aula: o professorarquivista não produz saber local, a pesquisa quase não existe no setor privado (SCHWARTZMAN; SCHWARTZMAN, 2002).

Corazza (2003), perspectivando, não o conteúdo das receitas, mas uma teoria geral do pensamento, ou seja, focando o espaço mental que o currículo traça, chamou esse currículo tipo receita culinária, de currículo-Assentado, cuja

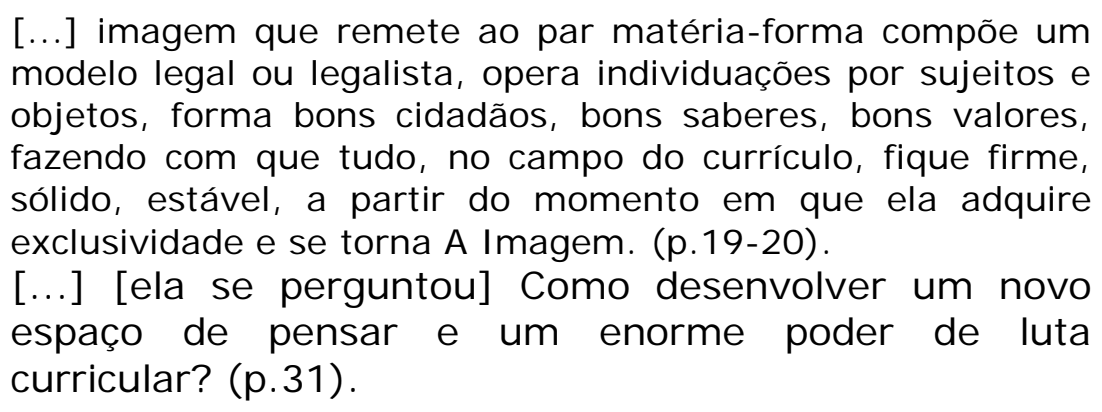

E então, a aula de psicologia se torna guerra. Só assim conseguimos resistir ou re-existir nesta formação acadêmica. Fazemos, pois, uma esquizoanálise do currículo (Gauthier, 2002).

\section{Um currículo esquizo}

ferramentas de trabalho:

[para abrir currículos]

1 abridor de problemas

1 encolhedor de inércias

1 esticador de horizontes

Manoel de Barros (2006) 
Não mais a superfície especular do currículo-Assentado, mas uma superfície de inscrição, como nos mostra Sandra Corazza que gosta de brincar com currículos - o dançarino, o vagamundo, 0 problemático, o gangue e tantos outros marginais. Queremos um currículo que nos convoque a pensar novos pensamentos para a invenção de uma psicologia em composição com o social daqui, das nossas vizinhanças, do Quilombo de Batalha (AMARAL; SILVA, 2009), da feira livre onde somos fregueses (SILVA, 2009), dos adolescentes em cumprimento de medida socioeducativa (MACIEL, 2009). Queremos transversalizar, conectando experiências, teorias, práticas, pensamentos, as palavras e as coisas. Linhas de fuga. Não queremos um currículo-Assentado, linha de montagem que produz em série acumuladores de capital humano.

Estamos falando de estratégias como linhas de fuga possíveis neste processo em andamento que é a formação acadêmica. Entre as grades que capturam o pensamento, existem espaços vazados. É por aí que esticamos a 'pista de corrida' - o curriculum - e pegamos velocidade, até alcançar a velocidade do pensamento criativo.

Abrir o currículo aos devires. No lugar de governamentalizar currículo como um dispositivo de produção de sujeitos normais, governados, dóceis poupadores de capital humano acontecimentalizar, isto é, questionar as evidências sobre as quais se apóiam os saberes, buscando as conexões, os jogos de força, os encontros, as estratégias que têm formado em um dado momento o que logo vai funcionar como evidência, universalidade e necessidade (FOUCAULT, 2003). Numa esquizoanálise do currículo, no lugar de grade curricular - organização de um saber já constituído e capturado em conteúdos a serem aprendidos e a partir do qual adquirimos competências - ficamos atentos para os agenciamentos curriculares que nos levam a experimentar. Daí que trocamos as competências pelas performances (GAUTHIER, 2002), antídoto para a inércia do currículo-Assentado.

Outra estratégia é anarquizar o arquivo, bagunçar as gavetas, desarrumar a ordem da expertise e a solenidade dos especialistas. Desinstitucionalizar o currículo. Liberar o pensamento da perspectiva arbórea (DELEUZE; GUATTARI, 1995). No lugar da árvore que organiza o saber em compartimentos estanques, o rizoma que permite transitar entre e através da multiplicidade de saberes. Transversalizar o currículo-Assentado. Fugir das categorias do hábito, isto é, da recognição baseada na representação, para maquinar uma desterritorialização dessa imagem dogmática do pensamento e inventar uma nova imagem do pensamento que acolha a diferença.

Neste ponto, o desemaranhar de linhas na cartografia do saber que estamos desenhando, tomando como provocação o analisador grade curricular, mostra nas tramas ocultas da micropolítica da formação 
em psicologia, um perigo: duas linhas se destacam. Uma das linhas é de segmentaridade dura, cristalizada, incrustada na própria alma, cultuada, desejada - a imagem dogmática do pensamento que controla a política curricular. De um lado, como macrodiscurso totalitário sobre a verdade de um saber-poder que promete a autorrealização do espírito humano nos moldes da perspectiva do projeto dominante, e, do outro lado, como micropolítica da cognição praticada na sala de aula, que estabelece uma relação com a aprendizagem como recognição para acumular saber e esculpir identidades serializadas (SILVA, 2001). A outra é uma linha de fuga que pensa o currículo sem pressupostos, sem imagem dogmática do pensamento, que se relaciona com a aprendizagem de uma forma que se aprendam não conteúdos, mas aprender a aprender, para que em cada situação se continue aprendendo e inventando a si mesmo e inventando um mundo "[...] no campo coletivo das multiplicidades e dos agenciamentos" (KASTRUP, 2007, p.223-224).

Neste ponto colocamos a seguinte questão: como se chega a ser o psicólogo que se é? O que pode uma formação em psicologia? Como funciona esse processo de formação?

Podemos responder de várias maneiras, inclusive, já começamos a responder a essas perguntas ao esboçar uma cartografia do saber, desemaranhando linhas do analisador grade curricular. Como é que numa formação construímos ou nos são construídos modos de ser no mundo pelos quais nos tornamos psicólogas/os? Como operam os saberes e os fazeres nas práticas psi na sociedade? Nesta cartografia destacamos dois planos e vamos puxar algumas linhas de cada plano. Primeiro, veremos o plano macro, plano molar das máquinas maiores, do que está estratificado, das práticas institucionais: a formação como instituição. O outro é um plano menor, um plano micro, do que não é visível, do que é da ordem do acontecimento, dos agenciamentos: a formação como prática de si.

\section{Formação como instituição}

É o sentido ativo, de produção de efeitos, que se resgata quando tomamos a instituição como processo, cruzamento de linhas de forças, produção de territórios provisórios. Regina Benevides de Barros (Barros, 1995, p.5)

Na perspectiva formação-instituição, dirigimos nosso interesse para o arcabouço de sustentação no seu plano molar, isto é, os cursos de Psicologia, iniciando com um breve percurso histórico da própria psicologia no Brasil, assunto que devia fazer parte do currículo e que no caso do grupo de estudantes que querem ser psicólogas e 
psicólogos foi uma das grandes ausências dessa experiência. Na nossa sala de aula, a psicologia brasileira não tem história. Aqui, a Psicologia só tem história geral, na versão de um manual americano, com uma professora-arquivista, dessas que leem transparências e que não admitem comentários. Era uma aula de culinária. Por que a instituição que vende o curso considerou que a história da mercadoria não era relevante?

Para Jacó-Vilela (2002), o importante não é aprender datas, fatos e nomes e voltar ao passado para fixar um 'marco zero', a origem de tudo. Entendemos que a autora abre caminhos para que pensemos na necessidade de uma cartografia que nos aponte as linhas e forças que fazem com que, em nossos cursos de graduação, a psicologia brasileira seja tomada como algo a-histórico.

No Brasil - primeiro país no mundo a regulamentar a Psicologia como profissão, em 1962 (BERNARDES, 2004) - já existia um domínio técnico-científico anterior à lei, com profissionais (chamados de psicologistas) atuando. Para Patto (1984), a Psicologia desde seus inícios formava técnicos do ajustamento, da correção de desvios, da resolução de crises, da exclusão dos que resistem à norma, e da conservação da ordem social vigente. Mancebo (1999) afirma que na década de 1970 surge a cultura psi caracterizada por um 'ethos' individualista e intimista, cúmplice da ditadura, aliada ao capitalismo, promotora do consumo, com ampla aceitação nas camadas médias urbanas e cujo veiculo principal foram os especialistas psi, responsáveis pela psicologização das demandas sociais e políticas. Mancebo sustenta que essa cultura psi marcou o campo de formação do psicólogo.

Com esse referencial comum, no mesmo ano da regulamentação, o Estado (Conselho Federal de Educação) definiu as disposições legais para os cursos de Psicologia e fixou o currículo mínimo. Segundo Bastos (2002), era um modelo limitado de atuação profissional, com predomínio da formação clínica para o atendimento individual em consultório particular. Atrelada ao padrão médico e construindo sua prática sob a influência da psiquiatria e da psicopatologia, a Psicologia Clínica se consolidou como profissão embalada no prestigio herdado do poder médico, mas sempre em uma posição subserviente de clínica inferior. A formação era tecnicista, e a teoria fragmentada e dissociada da prática, a qual estava orientada para o domínio de técnicas de medida e avaliação. Mancebo (1997) coloca a pesquisa como a grande ausente da formação, "caracterizando um quadro de formação passiva, onde o aluno transforma-se em ouvinte e repetidor dos conhecimentos 'prontos' que Ihe são repassados" (p.22). A pesquisadora afirma que os estágios foram alvo das maiores críticas pela sua carga horária reduzida e pelas poucas opções oferecidas Clínica, Trabalho e Escolar -, com amplo predomínio da Clínica. Em geral, não há produção de conhecimento, portanto, estudantes e 
professores são "apenas consumidores - no máximo, adaptadores de conhecimentos gerados pela ciência do primeiro mundo" (FRANCISCO; BASTOS, 1992, p.126).

Bernardes (2004) nos fala que na formação há uma marcada cisão entre ciência - teoria e disciplinas - e profissão, reduzida à prática, ao exercício profissional e às disciplinas práticas limitadas aos estágios. Essa dicotomia originou, por sua vez, três consequências que marcam a ferro a formação do psicólogo. A primeira, a cisão entre saber (a teoria vem primeiro) e fazer (a prática vem depois; para nós apenas no oitavo semestre). A segunda é a preferência pelas teorias importadas que são aplicadas sem nenhuma adaptação ao contexto cultural brasileiro. A terceira consequência, segundo o autor, é a preferência no currículo pelas disciplinas aplicadas, experimentalistas e biologicistas, marcando assim a hegemonia da Psicologia Aplicada, responsável pela especialização precoce, o tecnicismo e a fragmentação da formação.

Com este quadro, acabamos de descrever nosso curso de formação. Impressionante, a força do instituído na psicologia brasileira. A isso podemos chamar de uma sólida tradição, pois todas essas descrições são do modelo fundacional que tanto tem sido criticado e que continua presente e atuante em muitos cursos de graduação pelo Brasil afora, incluindo o nosso.

A cartografia desemaranhou algumas linhas duras, máquinas binárias molares e algumas linhas de fuga. Porque a voz está falando de uma formação poderíamos trazer agenciamentos que o acaso trouxe para a sala de aula e com os quais algumas composições foram feitas. Micropolíticas de uma formação.

\section{Formação como prática de si. Analisador: um desassossego}

Um desassossego se fez notar em nós: precisávamos problematizar o estado de inquietação e o desassossego que provocava em nós o encontro com essa psicologia maior que pretendia formar um certo profissional, uma determinada identidade do psicólogo. Havia uma incongruência, uma dissonância entre essa ciência psicológica e o que nosso corpo nos estava dizendo com esse estado de inquietação. Pela vivência que tínhamos do humano, sabíamos que é perpétua mudança, transformação constante, estados longe do equilíbrio. Poderia ser isso que nos inquietava, sentir que muitas dessas fórmulas que estávamos aprendendo eram como uma traição ao acontecer humano, uma tentativa de engessamento em um modelo, em uma forma.

Então, o acaso trouxe outros elementos até então desconhecidos. Chegaram como um bloco de carnaval, fora de tudo o que o currículo determinava para estudar. Falavam não em ser, mas em devir. 
Imediatamente sentimos a ressonância no nosso desassossego, pois o que mais incomodava era que tudo na formação negava a contínua mudança e este bloco chegava trazendo o devir, a imanência, a afirmação da diferença. Aprendemos a trabalhar com as marcas estados inéditos, diferentes e estranhos à consistência subjetiva de nossa atual figura - que se produzem em nosso corpo, em um registro invisível, a partir da composição de fluxos que nos atravessam e que vêm de todo tipo de ambientes, provocando desestabilização e desassossego pela diferença que se introduz, o que nos pressiona no sentido de criarmos um novo corpo que sente, pensa e age no registro dessas novas composições. Podemos dizer que encarnamos uma outra subjetivação, isto é, mudamos nossa singularização, nos tornamos outros, somos lançados em um constante devir (ROLNIK, 1993). Vimos então que o desassossego era produzido pela violência das marcas. Não era o que devia ser eliminado, mas o disparo de um corpo afetado pelas marcas e forçando o exercício do pensamento. A autora nos diz que o importante é a capacidade de se deixar violentar pelas marcas, o que não diz respeito a um eu subjetivo ou individual, mas às forças que atravessam o corpo e o afetam forçando-o a pensar. Como funciona essa capacidade? Por que todos não foram afetados no grupo de estudantes que queriam ser psicólogas e psicólogos? Tem a ver com produção de subjetividade? Temos aqui algo interessante para se pesquisar.

Neste ponto se faz necessário considerar o papel do professor na formação acadêmica. Para Rolnik (1993), o que o professor transmite é o modo e a perspectiva com a qual constrói seu trabalho com o pensamento enquanto exercício provocado pelas marcas. Neste sentido, diz a autora, não é um saber o que o professor transmite, mas um aprender, um criar, pois não é como sábio ou mestre que o professor-pensador se transmite, mas como aprendiz.

O professor é fundamentalmente um suporte para que o aluno possa desenvolver recursos psíquicos e teóricos para este aprendizado, que implica uma torção em seu modo de subjetivação. Recursos psíquicos para suportar 0 desassossego causado pela violência das marcas [...]. Recursos teóricos para a criação deste corpo conceitual [...]. Neste tipo de prática 'pedagógica' a relação entre professor e aluno é da ordem de uma cumplicidade, feita de uma crença amorosa na possibilidade que o aluno tem de desenvolver desta forma seu trabalho no pensamento, crença não menos amorosa na eficácia e no valor deste trabalho enquanto potencializador da capacidade de afirmação da vida. (ROLNIK, 1993, p.248-449, grifos nossos) 
Entendemos que se trata de um professor enquanto agenciador. Na nossa sala apareceu um - não pratica o mandarinato, não projeta transparências -, lança provocações. Trouxe um desenho.

Agenciamento: desenho da dobra - O diagrama de Foucault (Deleuze, 2006, p.128)

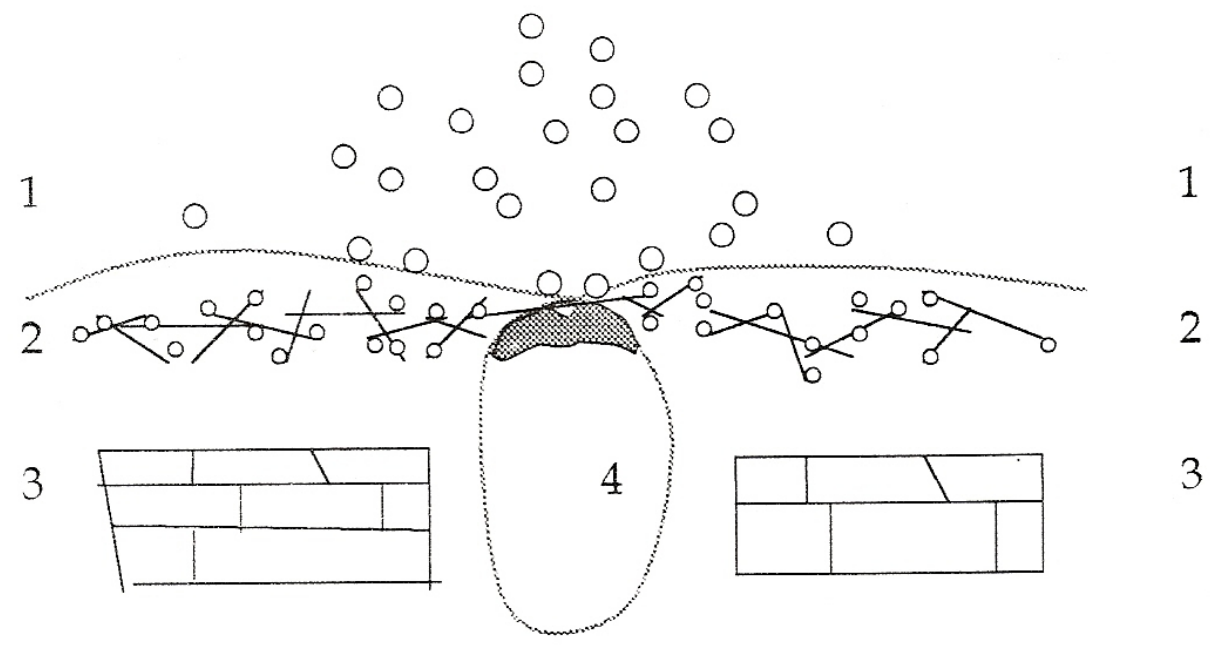
1. Linha do Fora
3. Estratos
2. Zona estratégica
4. Dobra (zona de subjetivação)

Figura 1 - Anotação do diário, aula da disciplina Exclusão Social (2006.1)

\begin{abstract}
Ao simples olhar, o desenho parece ter sido feito por uma criança. Mas ele não nos foi apresentado de vez, foi sendo .desenhado no quadro, parte por parte enquanto o professor explicava o processo de subjetivação segundo Foucault. Assim que quando apareceu a câmera central que chamou de zona de subjetivação, como efeito de uma dobradura do que era a linha do Fora, ficamos encantados, como crianças vendo o mágico fazer malabarismos. Uma sensação de "a ficha caiu". Fim da ingenuidade ${ }^{16}$.
\end{abstract}

O desenho teve a força de um fator de a(fe)tivação (ROLNIK, 2007), isto é, coisas, pessoas, um poema, um filme, elementos que até podem parecer insignificantes - como o desenho da dobra foi para muitos -, "podem muitas vezes, determinar mudanças radicais de direção e de vida, permitindo-nos compor outros e inesperados planos" (RODRIGUES, 2001, p.32). O desenho e a avalanche de conceitos novos nos atravessaram como um furacão.

Nunca mais fomos os mesmos, mudou a forma como nos víamos e como víamos os outros e o mundo. "A psicologia tem que desaderir do indivíduo que se torna contínuo na relação com o outro" (RODRIGUES, 2006, s/p). Na experiência do grupo de estudantes, para alguns dos que queriam ser psicólogas e psicólogos foi 
introduzida, não uma reforma, mas uma revolução. Uma revolução molecular (GUATTARI, 1987), no registro micro de uma sala de aula. Então, a formação não é mais uma formatação, mas a produção de uma subjetividade como prática de si.

A formação nunca é apenas a produção de um profissional, mas a produção de uma subjetividade na qual ficam incorporados modos de pensar, agir, sentir e perceber o mundo. Estamos sempre implicados e a importância do trabalho crítico está precisamente no fato de que essa é uma "experiência modificadora de si no jogo da verdade" (FOUCAULT, 1984, p.10). Para o pensador, "artes da existência" é um conjunto de práticas realizadas de forma voluntária como exercícios sobre si mesmo com o objetivo de transformar-se de tal maneira que o sujeito se torne um artífice da sua vida, fazendo dela um valor estético. Trata-se então de formação acadêmica, tomada como um campo no qual podemos constituir-nos enquanto humanos, não apenas enquanto profissionais. Com certeza, o profissional que se forma na graduação é o ser humano que se toma como matéria a modelar-se a si mesmo, a esculpir sua própria forma: a escultura de si para a superação da apatia e do niilismo contemporâneo. (ONFRAY, 1995).

Concordamos com Ferreira Neto (2004, p.190): "Os problemas da formação devem ser localizados dentro de um 'diagnóstico do presente' e este diagnóstico da atualidade recobre seus processos macro e micropolíticos". Se toda política é macro e micropolítica simultaneamente, é na dimensão micromolecular do cotidiano da formação na sala de aula que podemos abrir brechas, provocar fissuras, construir passagens para as linhas de fuga que possibilitam driblar as máquinas de devorar almas, saindo assim, da sonolência, da apatia e da imobilidade que nos deixam a mercê das forças que modelam subjetividades negociáveis.

Esse "mundo acadêmico" - parecido em todas partes - precisa da potência do delírio que como um vendaval arraste os saberesverdades, porque queremos inventar nossas próprias verdades, criar nossos próprios problemas, nosso próprio mundo, vivido na imanência de uma vida. Podemos enquanto psicólogos em formação, construir uma psicologia-agenciadora de linhas de fuga, de virtualidades cuja atualização possibilite a invenção de novas formas de ser/pensar/fazer/sentir. Quando a psicologia se tornar uma arte, quando fizermos a psicologia se tornar uma arte, estaremos nos fluxos de uma máquina de guerra para enfrentar os perigos do presente.

Por uma psicologia menor... 


\section{Referências}

ALTOÉ, S. Histórias de interseção entre psicoterapia institucional e análise institucional. In: RODRIGUES, H. de B. C.; ALTOÉ, S. (Org.). Saúdeloucura 8, Análise I nstitucional. São Paulo: Hucitec, 2004. p. 39-64.

AMADOR, F.; FONSECA, T. M. G. Da intuição como método filosófico à cartografia como método de pesquisa: considerações sobe o exercício cognitivo do cartógrafo. Arquivos Brasileiros de Psicologia, Rio de Janeiro, v. 61, n. 1, p. 30-37, 2009.

AMARAL; SILVA, E. I tinerários de Batalha e invenção ou como maquina um coletivo. 2009. 42f. Trabalho de Conclusão de Curso, Psicologia, FTC/VIC.

ANDERSON, P. Balanço do neoliberalismo. In: SADER, E. \& GENTILI, P. (Orgs.). Pós-neoliberalismo: as políticas sociais e o Estado democrático. Rio de Janeiro: Paz e Terra, 1995, p. 09-23.

BAPTISTA, L. A . S. A fábrica de interiores: a formação psi em questão. Niterói: EdUFF, 2000.

BAREMBLITT, G. Compêndio de análise institucional e outras correntes: teoria e prática. 5ạ ed. Belo Horizonte, MG: Instituto Felix Guattari, 2002.

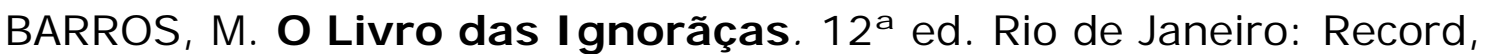
2006.

BARROS, R. B. Algumas questões sobre a ética. Revista do Departamento de Psicologia - UFF, Niterói, v. 1, n. 1, p. 4-9, 1995.

BASTOS, A . B. Perfis de formação e ênfases curriculares: o que são e por que surgiram? Revista do Departamento de Psicologia UFF, Niterói, v. 14, n. 1, p. 30-42, 2002.

BERNARDES, J. S. O debate atual sobre a formação em psicologia no Brasil: permanências, rupturas e cooptações nas políticas educacionais. 2004. 207f. Tese (Doutorado Psicologia Social) - Programa de Estudos Pós-Graduados em Psicologia Social, Pontifícia Universidade Católica de São Paulo, São Paulo.

BOURDIEU, P. Esboço de auto-análise. São Paulo: Companhia das Letras, 2005.

BOURDIEU, P.; WACQUANT, L. La nouvelle vulgate planétaire. Le Monde Diplomatique, Paris, maio, p. 6-7, 2000.

CORAZZA, S. Governamentalidade moral do currículo nacional. In: Que quer um currículo? Pesquisas pós-críticas em ēucucação. Petrópolis, RJ: Vozes, 2001, p.77-96.

. Noologia do currículo: Vagamundo, o problemático, e Asssentado, o resolvido. In: CORAZZA, S.; SILVA, T. T. Composições. Belo Horizonte: Autêntica, p. 34-19, 2003. 
COSTA, S. de S. G. Governamentalidade neoliberal, Teoria do Capital Humano e empreendedorismo. Educação \& Realidade, Porto Alegre, v. 34, n. 2, p. 171-186, maio/agosto, 2009.

DELEUZE, G. Conversações, 1972-1990. Rio de Janeiro: Ed. 34, 1992.

A imanência: uma vida... 1995. Dossiê Gilles Deleuze. Disponível em: <http://www.dossie_deleuze.blogger.com.br/>. Acesso em: 15 set. 2009.

Foucault. São Paulo: Brasiliense, 2006.

DELEÜZE, G.; FOUCAULT, M. Os intelectuais e o poder. In: FOUCAULT, M. Microfísica do poder. 4a ed. Rio de Janeiro: Graal, 1984.

DELEUZE, G.; GUATTARI, F. O Anti-Édipo: capitalismo e esquizofrenia. Rio de Janeiro: I mago, 1976.

$\overline{1} \overline{9} \overline{7}$.

Kafka: para uma literatura menor. Rio de Janeiro: Imago, $\overline{1} \overline{9} \overline{9} \overline{5}$.

Mil Platôs - capitalismo e esquizofrenia. v. 1. RJ : Ed. 34,

DELEUZE, G.; PARNET, C. Diálogos. São Paulo: Escuta, 1998.

FERREIRA NETO, J. L. A formação do psicólogo. Clínica, social e mercado. São Paulo: Escuta, 2004; Belo Horizonte: Fumec/FCH, 2004.

FOUCAULT, M. Arqueologia do saber. Petrópolis: Vozes, Lisboa: Centro do Livro Brasileiro, 1972.

História da sexualidade 2: o uso dos prazeres. Rio de Janeiro: Graal, 1984.

. O sujeito e o poder. In: DREYFUS, H.; RABINOW, P. Michel Foucault, uma trajetória filosófica. Para além do estruturalismo e da hermenêutica. Rio de Janeiro: Forense Universitária, p. 231-249, 1995.

Em defesa da sociedade. Curso no Collège de France (1975-1976). São Paulo: Martins Fontes, 1999.

Estratégia poder-saber. Rio de Janeiro: Forense Universitária, 2003.

Nacimiento de la Biopolítica. Curso en el Collège de France (1978-1979). Buenos Aires: Fondo de Cultura Económica, 2007.

Topologias. (Conferencia radiofônica em France-Culture 07/12/1966). Fractal, n. 48. México: Conaculta, 2008a. Disponível em: $\quad<$ http://www.fractal.com.mx/RevistaFractal48 MichelFoucault.html>. Acesso em: jan. 2009.

Aula de 1 o de fevereiro de 1978. In: Segurança, Território, População. Curso dado no Collège de France (19771978). São Paulo: Martins Fontes, 2008b. 
Vigiar e punir: nascimento da prisão. 35. ed. Petrópolis, RJ: Vozes, 2008c.

FRANCISCO, A. L.; BASTOS, A. B. Conhecimento, formação e prática - o necessário caminho da integração. In: CONSELHO FEDERAL DE PSICOLOGIA. Psicólogo Brasileiro. Construção de novos espaços. Campinas: Editora Átomo, 1992.

GALLO, S. Conhecimento, transversalidade e currículo. In: 18ạ REUNIÃO ANUAL DA ANPEd, Programa e resumos. Associação Nacional de Pós-Graduação e Pesquisa em Educação, ANPEd, 1995. p.97.

GAUTHIER, C. Esquizoanálise do currículo. In: DOSSIÊ GILLES DELEUZE. Educação e Realidade, Porto Alegre, v. 27 n. 2, p. 143155, jul./dez. 2002.

GOMIDE, P. I. C. A formação acadêmica: onde residem suas deficiências? In: CONSELHO FEDERAL DE PSICOLOGIA. Quem é o psicólogo brasileiro? São Paulo: EDICON, 1988.

GUATTARI, F. Revolução molecular: pulsações políticas do desejo. 3a ed. São Paulo: Brasiliense, 1987.

GUATTARI, F.; ROLNIK, S. Micropolítica: cartografias do desejo. 7a ed. Petrópolis, RJ: Vozes, 2005.

HESS, R. O movimento da obra de René Lourau (1933-2000). In: ALTOÉ, S. (Org.). René Lourau: analista institucional em tempo integral. São Paulo: Hucitec,p. 15-46, 2004.

JACÓ-VILELA, A. M. Idas e vindas do curso de Psicologia no Brasil. Revista do Departamento de Psicologia - UFF, Niterói, v. 14, n. 1, 2002, p. 11-22.

KASTRUP, V. A invenção de si e do mundo. Uma introdução do tempo e do coletivo no estudo da cognição. Belo Horizonte: Autêntica, 2007.

LEMKE, T. Foucault, governmentality and critique. Rethinking Marxism conference, University of Amherst MA, 21-24 september 2000.

LISPECTOR, C. Água viva. Rio de Janeiro: Rocco, 1998.

LOURAU, R. A Análise I nstitucional. Petrópolis: Vozes, 1975.

MACIEL, R. B. Territórios da "vida loka": cartografias do dispositivo da criminalidade e suas produções de subjetividade. 2009. 45f. Trabalho de Conclusão de Curso, Psicologia, FTC/VIC

MANCEBO, D. Formação do psicólogo: uma breve análise dos modelos de intervenção. Psicologia. Ciência e Profissão, Brasília, v. 17 , n. 1,1997 , p. 20-27.

Formação em Psicologia: Gênese e primeiros desenvolvimentos. In: JACÓ-VILELA, A. M.; JABUR, F.; RODRIGUES, H. de B. (Org.). Clio-psyché: Historias da psicologia no Brasil. Rio de J aneiro: UERJ, 1999.

MINISTÉRIO de Educação. Instituto Nacional de Estudos e Pesquisas Educacionais Anísio Teixeira (INEP). Resumo Técnico. Censo da 
Educação Superior 2007. Brasília DF, 2009. Disponível em: <http://www.inep.gov.br/download/superior/censo/20 07/Resumo_tecnico_2007.pdf >. Acesso em: 30 out. 2009. MOREIRA, A F.; SILVA, T. T. Sociologia e teoria crítica do currículo: uma introdução. In: __.. (Orgs.). Currículo, cultura e sociedade. 8a ed. São Paúlo: Cortez, 2005.

ONFRAY, M. A escultura de si: a moral estética. Rio de Janeiro: RocCO, 1995.

PATTO, M. H. S. Psicologia e I deologia. São Paulo: T. A. Queiroz, 1984.

PAULON, S. M. A análise de implicação como ferramenta na pesquisaintervenção. Psicologia e Sociedade, Porto Alegre, v. 17, n. 3, 2005, p. 18-25.

PETERS, M. Governamentalidade neoliberal e educação. In: SILVA, T. T. (Org.). O sujeito da educação: estudos foucaultianos. 5a ed. Petrópolis, RJ: Vozes, p. 211-224, 2002.

RODRIGUES, V. Corpo, Técnica e Mídia: Simulações de Potência vol. II. 2001. 280f. Dissertação (Mestrado em Comunicação e Mercado) - Faculdade de Comunicação Social Cásper Líbero, São Paulo.

Anotações das aulas da disciplina "Exclusão Social". Graduação em Psicologia. (FTC-VC). Caderno pessoal, Vitória da Conquista, março, 2006.

RODRIGUES, H. B. C.; SOUZA, V. B. A análise Institucional e a profissionalização do psicólogo. In: SAIDON, O.; KAMKHAGI, V. R. (Orgs.) Análise Institucional no Brasil. Rio de Janeiro: Espaço e Tempo, p. 17-35, 1987.

ROLNIK, S. Pensamento, corpo e devir: uma perspectiva ético/estético/política no trabalho acadêmico. Cadernos de subjetividade. Núcleo de Estudos e Pesquisas da Subjetividade do Programa de Estudos Pós-Graduados em Psicologia Clínica da PUCSP, São Paulo, v. 1, n. 2. São Paulo, 1993.

Cartografia sentimental: transformações contemporâneas do desejo. Porto Alegre: Sulina; Editora da UFRGS, 2007.

SADER, E. Público versus mercantil. Folha de São Paulo, São Paulo, 19 jun. 2003, p. 3.

SCHWARTZMAN, J.; SCHWARTZMAN, S. O ensino superior privado como setor econômico. Trabalho realizado por solicitação do Banco Nacional de Desenvolvimento Econômico e Social (BNDES), 2002.

SILVA, M. B. Povoar as ruas, encontrar a cidade: potências de apropriação do espaço urbano e modos de subjetivação na feira livre. 2009. 53f. Trabalho de Conclusão de Curso, Psicologia, FTC/VIC, Vitória da Conquista.

SILVA, T. T. O projeto educacional moderno: identidade terminal? In: VEIGA-NETO, A. (Org.). Crítica pós-estruturalista e educação. Porto Alegre: Sulina, p. 245-260, 1995. 
Documentos de I dentidade: uma introdução às teorias do currículo. Belo Horizonte: Autêntica, 1999.

O currículo como fetiche: a poética e a política do texto curricular. Belo Horizonte: Autêntica, 2001.

\title{
Endereço para correspondência Marcia Moraes
}

Campus do Gragoatá - Rua Prof. Marcos Waldemar de Freitas Reis, s/n, bloco O, sala 214 - Gragoatá - Niterói - RJ - CEP: 24210-201

Endereço eletrônico: mazamoraes@gmail.com

\section{Nedelka Solís Palma}

Cidade Universitária Prof. Aloísio de Campos Av. Marechal Rondon, s/n, Jardim Rosa Elze CEP: 49.100.000, São Cristóvão.

Endereço eletrônico: nedelkapalma@yahoo.com.br

Valter A. Rodrigues (in memoriam)

Recebido em: 14/03/2011

Reformulado em: 09/06/2011

Aceito para publicação em: 13/06/2011

Acompanhamento do processo editorial: Adriana Benevides Soares

\begin{abstract}
Notas
* Mestranda em Psicologia pela UFS. Graduada em Psicologia pela Faculdade de Tecnologia e Ciência (FTC), unidade de Vitória da Conquista, Ba. Membro do coletivo USINA - estudos e práticas micropolíticas.

**Psicólogo [PUC-SP], Mestre em Comunicação [Faculdade Cásper Líbero-SP].

Coordenador do coletivo USINA - estudos e práticas micropolíticas.

*** Professora Associada, Departamento de Psicologia / Programa de Pós-

graduação em Psicologia. Universidade Federal Fluminense. Bolsista de

Produtividade em Pesquisa/2 do Cnpq.

${ }^{1} \mathrm{O}$ esboço de autoanálise tal como é proposto neste artigo é inspirado em algumas ideias de Bourdieu (2005).

${ }^{2} \mathrm{~A}$ esquizoanálise como um dos referenciais teóricos desta análise. A propósito, ver DELEUZE, GUATTARI (1976).

3"O essencial são os intercessores. A criação são os intercessores. Sem eles não há obra. Podem ser pessoas [...] Fictícios ou reais, animados ou inanimados, é preciso fabricar seus próprios intercessores." (DELEUZE, 1992, p.156).

${ }^{4}$ Heterotopia: conceito proposto por Foucault para designar lugares cuja existência é real, localizáveis, embora pareçam se encontrar por fora de todos os lugares comuns; parecem ter uma relação de neutralização, suspensão, ou inversão com os demais lugares comuns. (FOUCAULT, 2008a).

${ }^{5}$ Menor aqui diz respeito ao que Deleuze \& Guattari chamaram de "literatura menor" ao analisar os deslocamentos que Kafka fez com respeito à literatura hegemônica ou "literatura maior". Interessa a potência subversiva, a marginalidade, a abertura nas concepções cristalizadas e estereotipadas dessa voz menor e sua qualidade intensiva, desterritorializante: uma voz fuga que incorpora as três características de uma literatura menor: a desterritorialização da língua, a ramificação do individual no imediato-político e o agenciamento coletivo de enunciação. (DELEUZE \& GUATTARI, 1977).

${ }^{6}$ Deleuze (1995) fala da indeterminação de uma vida no seu último texto $A$ imanência: uma vida...
\end{abstract}


${ }^{7}$ Orlandi (2009) proporcionou alguns dos elementos desta construção que deixa bem claro que não se trata de uma narrativa autobiográfica.

${ }^{8}$ Dois anos depois, outra faculdade privada também passou a oferecer um curso de Psicologia.

${ }^{9}$ Os dados do último Censo da Educação Superior (2007) mostram que de um total de 2.281 Instituições de Educação Superior (IES), 89\% são privadas; foram oferecidos um total de 23.488 cursos dos quais, $71,91 \%$ correspondem às IES privadas, as quais são responsáveis por $74,6 \%$ do total de matrículas. (Ministério de Educação, INEP, 2009). Para Bernardes (2004), o MEC até hoje desconhece o número total de cursos de psicologia no Brasil.

${ }^{10}$ Para Anderson (1995), o neoliberalismo surge como uma reação teórica e política contra o intervencionismo do Estado de Bem-estar social.

${ }^{11}$ Não confundir estado mínimo com estado fraco; como argumenta Gentili (1995), o estado neoliberal pós-fordista é um estado forte, autoritário e antidemocrático.

${ }^{12}$ Dados do Censo Educacional 2007 mostram que de um total de 2.281 IES, 92,5\% são faculdades isoladas ou integradas, isto é, instituições não universitárias, (Ministério de Educação, INEP, 2009). A IES na qual esta experiência de formação acadêmica se efetua é desse tipo.

${ }^{13}$ Conjunto de técnicas que surgiram para organizar a produção capitalista articulando dois níveis de captura: o individual, isto é, a captura do corpo que devia ser disciplinado por instituições como a escola, a prisão, a fábrica, o quartel (anátomopolítica do corpo humano) e o massificante que faz dos fenômenos da espécie (nascimento, morte, doenças, etc.) a captura do homem-espécie, configurando uma biopolítica.

${ }^{14}$ Diário de campo, anotação para o relatório de estágio curricular, VIII semestre, 2008.2.

${ }^{15}$ Estamos tomando essa frase de Baptista (2000, p. 31).

${ }^{16}$ Anotação do diário, aula da disciplina Exclusão Social (2006.1). 